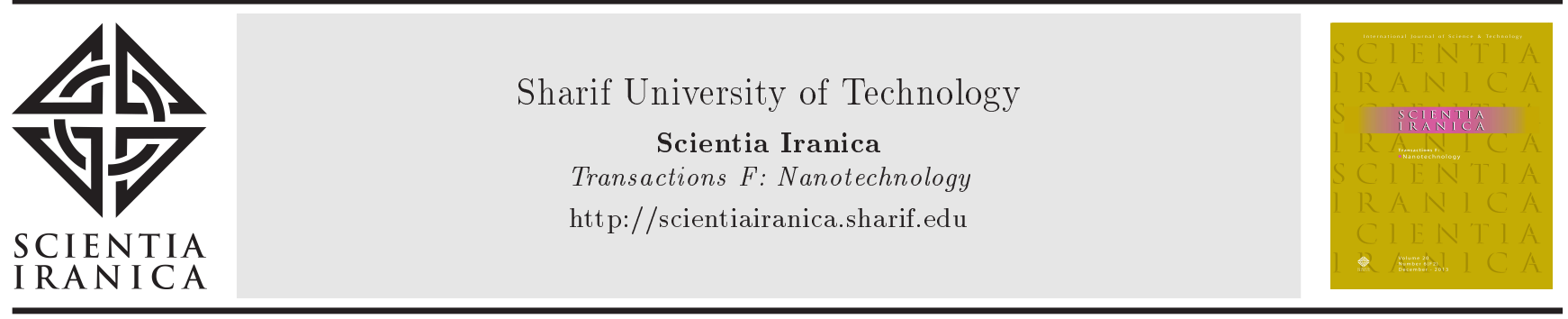

\title{
Electrochemical determination of glutathione in hemolyzed erythrocytes
}

\author{
M. Mazloum-Ardakani ${ }^{\mathrm{a}, *}$, Z. Tavakolian-Ardakani ${ }^{\mathrm{a}}$, and S.H. Banitaba ${ }^{\mathrm{b}}$ \\ a. Department of Chemistry, Faculty of Science, Yazd University, Yazd, 89195-741, Iran. \\ b. Department of Chemistry, Payame Noor University, Tehran, 19395-4697, Iran.
}

Received 26 April 2019; received in revised form 21 December 2019; accepted 3 March 2020

\section{KEYWORDS \\ Multi-walled carbon \\ nanotubes; \\ Glutathione; \\ Erythrocytes; \\ Formazon; \\ Electrochemical \\ determination.}

\begin{abstract}
The physiological significance of determining glutathione (GSH) and its oxide form is quite clear in terms of its applications in clinical practices such as diagnostic experiments for diabetes, Parkinson's disease, and cancers. Such important determination still needs the development of certain experimental procedures that are easy, fast, and cheap enough to implement. These procedural advantages can be provided through electrochemical methods. Therefore, in this study, on the surface of a Glassy Carbon Electrode (GCE), a composite of functionalized multi-walled carbon nanotubes (MWCNTs) and formazan was used as a mediator to determine GSH electrochemically. The results indicated that this modified GCE was electrocatalytically very active for glutathione oxidation. Several techniques including Cyclic Voltammetry (CV), scanning electron microscopy, and Differential Pulse Voltammetry (DPV) were applied to characterize the electrode. In addition, such kinetic parameters as the charge transfer rate constant and the transfer coefficient were calculated. In optimized conditions, there was a linear relationship between the DPV peak current of GSH oxidation and GSH concentration in the ranges of 1.0-100.0 and 100.0-800.0 $\mu \mathrm{M}$ at $\mathrm{pH}$ 7.0. As for the detection limit, it was found to be $0.73 \mu \mathrm{M}$. Once put into practice, the devised method proved to be capable of measuring GSH in blood samples.

(C) 2020 Sharif University of Technology. All rights reserved.
\end{abstract}

\section{Introduction}

Glutathione (GSH) is known as a biological compound that contains a thiol group. This intracellular thiol compound has a significant role in various biological functions such as redox cycle, electron transfer, protein synthesis, metabolism, and catabolism. Glutathione serves as an enzyme cofactor, disposing poison with high concentrations of heavy metals and setting up

*. Corresponding author. Tel.: 00983518211670 ;

Fax: 00983518210644

E-mail address: mazloum@yazd.ac.ir ( $M$.

Mazloum-Ardakani)

doi: $10.24200 /$ sci.2020.53355.3198 protection against damages caused by irradiation. It is also an important factor in increasing the lifespan of Red Blood Cells (RBC), acting as an antioxidant and an inhibitor of free radicals. Glutathione can release free radicals derived from oxygen, which may contribute to the development of various diseases like diabetes [1], Parkinson [2], Alzheimer [3], and some types of cancer [4-6]. The glutathione level in blood can be an index of its level in tissues. Thus, measuring GSH in the blood is a way of identifying disease risks [7].

Glutathione concentration in red blood cells lies within a milli molar range, but within a micro molar range in the plasma. In normal conditions, glutathione concentration in those cells varies in the range of 0.5 to $10 \mathrm{mmol} \mathrm{L}^{-1}[8,9]$. At least, $99 \%$ of glutathione exists in 
red blood cells, $16 \%$ of which is connected to proteins. Only $0.5 \%$ of GSH is detected in the plasma [10]. Therefore, developing a simple, selective and sensitive measuring technique to determine the amount of GSH is important. So far, several chemical methods have been applied to measure GSH: spectrofluorimetry [11] chromatography [12], analysis of flow injection [13], and enzymatic methods [14]. Most of these methods, however, include difficult steps in sample preparation. Low sensitivity and necessity for derivation are the other disadvantages that account for the reduced use of these methods. In contrast, electrocatalytic methods provide such benefits as simplicity, inexpensiveness, high sensitivity, reproducibility, and easy miniaturization [15].

In this work, following the studies already done by our team to improve the surface of Glassy Carbon Electrodes (GCEs) with different modifiers for the measurement of various biological species and, further, using superior properties of nanoparticles for different methods [16-23], a GCE modified with formazan and multi-walled carbon nanotubes (MWCNTs) is applied to determine GSH concentration. Over recent decades, different electrochemical methods have been used to evaluate GSH in various samples [24-30]. For example, Munteanu et al. developed an electrochemical method to study the effects of the main biological forms of thiols such as homocysteine, cysteine, and GSH (oxidized and reduced forms) on the $\mathrm{Cu}^{2+/ 0}$ system. They could determine GSH at a detection limit of $0.18 \mu \mathrm{M}$ within the range of $4-7 \mu \mathrm{M}$ and at a detection limit of 0.05 $\mu \mathrm{M}$ within the range of $0.1-3 \mu \mathrm{M}$ at $\mathrm{pH}$ levels of 1.8 and 4.7, respectively [26]. Ndamanisha et al. used the electrochemical activity of ordered mesoporous carbon (OMC) to measure cysteine $(\mathrm{CySH})$ and glutathione (GSH). They illustrated the great importance of the arranged structure of OMC. It was found that due to its great surface area, appropriate porous structure, and big pore content, OMC can be a promising material for electrocatalysis and devastation of structures that result from the decrement of electrochemical and electrocatalytic properties [29]. Tang et al. reported a procedure for the electrochemical oxidation of glutathione and determined it at an aligned carbon nanotube (CNT) electrode. This electrode showed good electrochemical efficiency for electron transfer reactions. The method was used to determine GSH in the linear range of $0.4-16.4 \mu \mathrm{M}$ and a detection limit of $0.2 \mu \mathrm{m}$ [30].

This study develops an inexpensive, simple method to electrochemically determine GSH at a high speed rate, a low detection limit, and a wide linear dynamic range. For this purpose, a GCE was modified with a composite of MWCNTs and (2Z,4E)-3-(3,4dihydroxyphenyl)-1,5-bis (2,4-dinitrophenyl) formazan (DPBDF). Then, the modified electrode was employed to study the electrocatalytic oxidation of GSH through $\mathrm{CV}$ and DPV. It was also of use to assay GSH in human erythrocytes as real samples. These experiments conducted on GSH were based on the electrochemical behavior of thiol compounds, as discussed by Abiman et al. in 2007 [31].

\section{Materials and methods}

All the solutions were provided freshly with double distilled water. GSH was purchased from SigmaAldrich (Taufkirchen, Germany), MWCNTs from Nanostartech Co., and sulfuric acid, nitric acid, $\mathrm{Na}_{2} \mathrm{H}_{2}$ EDTA, sulfosalicylic acid, phosphoric acid, and ammonia from Merck. Moreover, DPBDF, as a modifier, was synthesized by the following method.

\subsection{Procedure for the synthesis of (2Z,4E)-3-(3,4-dihydroxyphenyl)-1,5-bis (2,4-dinitrophenyl) formazan (DPBDF)}

A mixture of (2,4-dinitrophenyl)hydrazine $(1.0 \mathrm{mmol})$ and 3,4-dihydroxy benzaldehyde (1.0 mmol, $138 \mathrm{mg}$ ) was stirred at room temperature in $5 \mathrm{ml}$ of ethanol for a certain period of time. This occurred with five drops of glacial acetic acid added to it as a catalyst. After completing the conversion, a red solid was obtained. Then, it was filtered and washed with cold ethanol. The resulting 3,4-dihydroxybenzaldehyde-2,4dinitrophenylhydrazone $(318 \mathrm{mg}, 1 \mathrm{mmol})$ together with $500 \mathrm{mg}$ of sodium acetate (solution A) was dissolved in hot methanol $(15 \mathrm{ml})$ under stirring in the reflux conditions and kept at room temperature for the subsequent coupling reaction. Then, 2,4-dinitroaniline (1 mmol, $183 \mathrm{mg}$ ), concentrated hydrochloric acid (1 $\mathrm{mL}$ ), and ice water were mixed and cooled down to $0^{\circ} \mathrm{C}$. To this solution was added a solution of $69 \mathrm{mg}$ of $\mathrm{NaNO}_{2}$ and $10 \mathrm{~mL}$ of water dropwise under regular stirring. The new solution obtained (solution B) was kept at temperatures $0-5^{\circ} \mathrm{C}$. In the next step, the phenyl hydrazone solution (solution A) was placed in an ice-water bath, and the diazonium chloride (solution B) was added to it dropwise under stirring at $0-5^{\circ} \mathrm{C}$. After two hours, the resulting cherry red material was filtered, crystallized from ethanol:water (60:40), and dried in vacuo. Finally, DPBDF was characterized by FT-IR and NMR spectroscopy, as presented in Figures S.1 and S.2 in the Supplementary Material. The FTIR spectra of DPBDF indicate absorption bands at $3459 \mathrm{~cm}^{-1}$ and 3348 , which are attributed to the $\mathrm{OH}$ and NH groups, respectively. Moreover, the appearance of the absorption bands at $1616 \mathrm{~cm}^{-1}, 1574 \mathrm{~cm}^{-1}$, and $1493 \mathrm{~cm}^{-1}$ indicates the existence of aromatic $\mathrm{C}=\mathrm{C}$ bands, $-\mathrm{C}=\mathrm{N}$-hydrazine, and $-\mathrm{N}=\mathrm{N}$-azo bands in combination. The absorption bands at $1546 \mathrm{~cm}^{-1}$ and $1362 \mathrm{~cm}^{-1}$ are the reason for the presence of $\mathrm{NO}_{2}$ group (Figure S.1 in Supplementary Material). 
The data obtained from the NMR spectra also show the successful construction of DPBDF (Figure S.2 in Supplementary Material).

\subsection{Preparation of functionalized $M W C N T$ and a composite of functionalized $M W C N T / D P B D F$}

The synthesis of carboxylated MWCNT was done in accordance with the reference method, with certain minor modifications made to it [32]. Briefly, $1.0 \mathrm{~g}$ of MWCNT was mixed with $75.0 \mathrm{~mL}$ of sulfuric acid and $25.0 \mathrm{~mL}$ of nitric acid. The mixture was refluxed at $50^{\circ} \mathrm{C}$ for as long as 24 hours and, then, cooled down to room temperature. What resulted was a stable black dispersion that was later neutralized with diluted ammonia, filtered, and dried at $85^{\circ} \mathrm{C}$ for four hours. To prepare an MWCNT/DPBDF composite (C-MWCNT/DPBDF), $10.0 \mathrm{mg}$ of the dried functionalized MWCNT sample was added to $10.0 \mathrm{~mL}$ of dimethylformamide (DMF) under ultrasonication for 1 hour. Then, $15 \mathrm{mg}$ of DPBDF was added to it, and the mixture was sonicated for two minutes. The solution was slowly stirred for 36 hours, followed by centrifugation at $6000 \mathrm{rpm}$ for six minutes. The obtained solid residue was dried at $40^{\circ} \mathrm{C}$.

\subsection{Fabrication of the modified electrode}

A GCE polished with alumina slurry was washed with distilled water and dried up in the air. A suspension of C-MWCNT/DPBDF diluted in a solution of ethanol and distilled water (at a volume ratio of 1:1) was dropped on the surface of the GCE. Then, it was left to be air-dried. For the optimization purpose, a solution containing $2.0 \mathrm{mg}$ of the modifier (CMWCNT/DPBDF) was prepared and cast on the surface of the electrode. The effect of the modifier was investigated in various volumes in the range of $1.5-5.0 \mu \mathrm{L}$. The optimized amount selected for the experiments was $3.0 \mu \mathrm{L}$.

\section{Results and discussion}

\subsection{Characterization of the prepared functionalized $M W C N T$ and $C-M W C N T / D P B D F$}

The functionalized MWCNT and C-MWCNT/DPBDF were characterized by SEM, and the images are provided in Figure 1(a) and (b). Figure 1(a) displays the MWCNTs with approximately $700 \mathrm{~nm}$ in length and $47 \mathrm{~nm}$ in the outer diameter. CNTs with strong oxidation agents, such as nitric acid and sulfuric acid, can afford the intense etching of their graphitic surface. This results in producing shorter tubes with a high number of erratic sites [33]. Figure 1(b) displays the SEM image of C-MWCNT/DPBDF. It clearly shows the good connection of DPBDF to MWCNTs. This connection increases the surface area and the catalytic
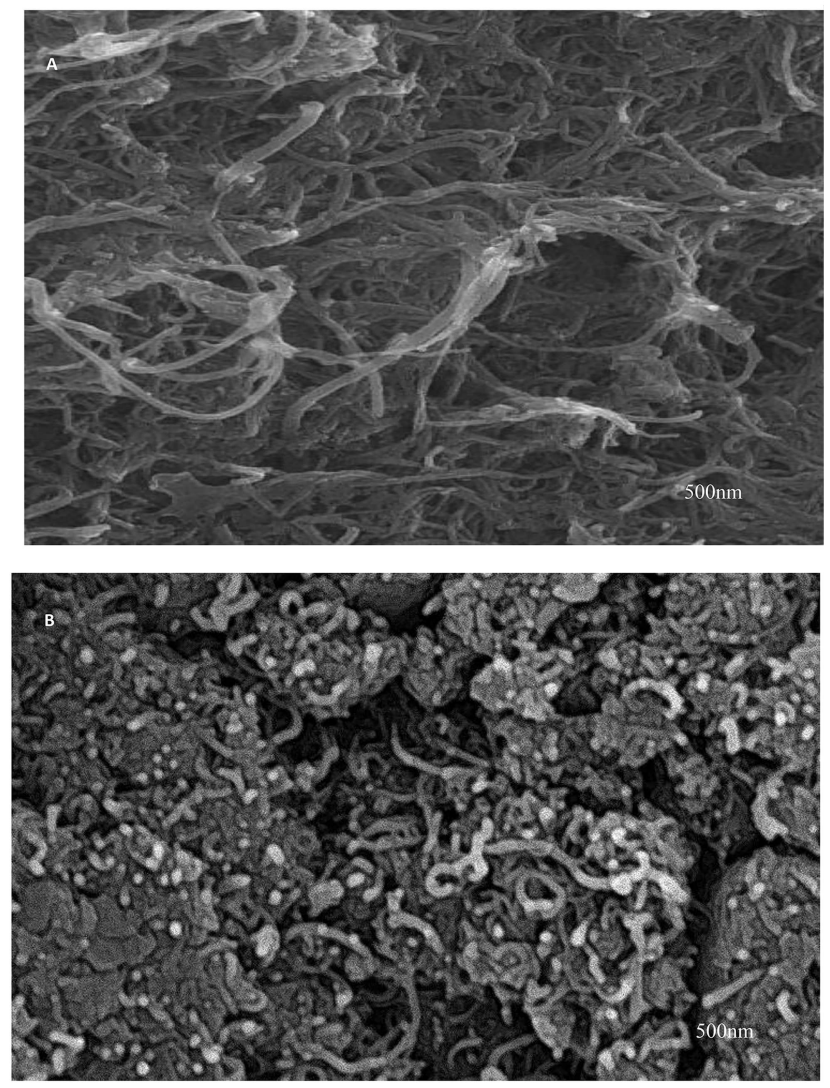

Figure 1. SEM image of (a) functionalized MWCNT and (b) c-MWCNT/DPBDF.

effect of the material. It also enhances the uniformity of the surface. As can be seen in the figure, DPBDF is scattered on the surface of the MWCNTs. The results suggest the successful preparation of these compounds.

\subsection{Electrochemical characterization of the modified electrode}

Kinetic parameters could be calculated by CV. This method was applied to characterize the electrode already modified. The CV tests were done in a phosphate buffer solution at $\mathrm{pH} 7.0$ and a scan rate of $20 \mathrm{mV} \mathrm{s}^{-1}$. Figure 2 shows the CVs of the bare GCE and C-MWCNT/DPBDF/GCE in a phosphate buffer solution. As observed in the curve a, there is no peak in the $\mathrm{CV}$ of the bare GCE, while, in the curve b, the electrode modified with C-MWCNT/DPBDF displays reproducible anodic and cathodic peaks with Epa and Epc at 0.281 and $0.173 \mathrm{~V}$, respectively, vs. $\mathrm{Ag} / \mathrm{AgCl}$ $(3.0 \mathrm{M} \mathrm{KCl})$. The inset in Figure 2 displays the CVs of the bare GCE (grey curve) and DPBDF/GCE (red curve) in a phosphate buffer solution. As expected, the DPBDF modified electrode exhibits a redox peak current. The peak of C-MWCNT/DPBDF/GCE has a larger current than the peak DPBDF/GCE, indicating the MWCNT effect. Based on the references presented, it is shown that the DPBDF redox couple possesses a quasi-reversible behavior $[34,35]$. 


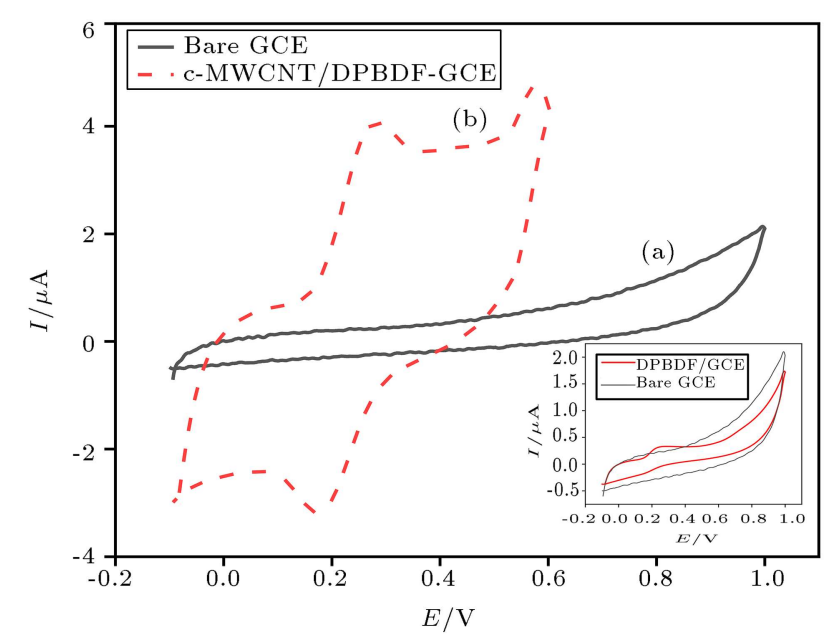

Figure 2. Cyclic voltammograms of (a) bare GCE and (b) c-MWCNT/DPBDF-GCE in a phosphate buffer solution $(\mathrm{pH} 7.0)$ at a scan rate of $20 \mathrm{mV} \mathrm{s}^{-1}$.

The electrochemical behavior of C-MWCNT/ DPBDF-GCE was investigated at different $\mathrm{pH}$ values through CV (Figure 3). Variations of the anodic and cathodic peak potentials, as the function of $\mathrm{pH}$, are shown in Figure 3(a). In both cases, the plots appear as straight-line curves with slopes of about $60.0 \mathrm{mV} / \mathrm{pH}$. This implies that the system follows the Nernst equation, representing the reaction for the transfer of a pair of electrons and a pair of protons. The plots of the cathodic and anodic peak currents $\left(I_{p}\right)$ linearly depend on $\nu$ in the range of $10-700 \mathrm{mV} \mathrm{s}^{-1}$ (Figure 3(b)). This indicates that the redox process occurs in a diffusionindependent surface-confined manner. The transfer coefficient, $\alpha$, and the apparent rate constant, $k-s$, for the surface-confined redox couple were considered in accordance with the Laviron procedure. Figure 3(c) reveals the variation of the peak potentials $\left(E_{p}\right)$ as the function of the scan rate logarithm.

As can be observed, at scan rates above $0.2 \mathrm{~V}$ $\mathrm{s}^{-1}$, the plots become linear. With the slopes of the linear sections, it is possible to calculate $\alpha_{c}$ and $\alpha_{a}$ (i.e., cathodic and anodic transfer coefficients) as the kinetic parameters. The estimated value of $\alpha_{a}$ is 0.67 . The constant for the rate of electron transfer between the modifier and the GCE can be determined by Eq. (1):

$$
\begin{aligned}
\log k_{s} & =\alpha \log (1-\alpha)+(1-\alpha) \log \alpha-\log \frac{R T}{n F \vartheta} \\
& -\alpha(1-\alpha) \frac{n F \Delta E_{P}}{2.3 R T}
\end{aligned}
$$

where $n$ stands for the number of the electrons involved in the redox reaction of the modifier, $\vartheta$ represents the potential scan rate, and other signs convey their conventional meanings. Through Eq. (1), the value of $k_{s}$ was found to be $5.0 \times 10^{-3} \mathrm{~s}^{-1}$.

\subsection{Electrochemical characterization of the modified electrode (C-MWCNT/DPBDF-GCE) for glutathione}

A comparison was made for the electrocatalytic oxidation of GSH on the surfaces of a bare GCE and a modified GCE. As observed in Figure 4, the oxidation of GSH on the surface of the modified electrode caused the anodic peak current to rise, but caused the cathodic peak current to decline. This process may be due to the coupling of a chemical reaction and an electron transfer reaction.

The impact of the scan rate upon the electrochemical oxidation of GSH on the surface of the modified electrode was studied through $\mathrm{CV}$ (Figure 5(a). Figure $5(\mathrm{~b})$ shows a plot peak current versus $v^{1 / 2}$. It can be understood that the current was diffusioncontrolled. The peak potential of GSH oxidation shifted to more positive values with a rise in the scan rate. In this regard, a kinetic limitation could be felt in the electrochemical reaction. As depicted in the figure, due to the rise of the scan rate, the cathodic peak current rose too. This is because, within a short experiment time at a high scan rate, the time would not be enough for a catalytic reaction to occur between oxidized DPBDF and GSH. Accordingly, in this study,

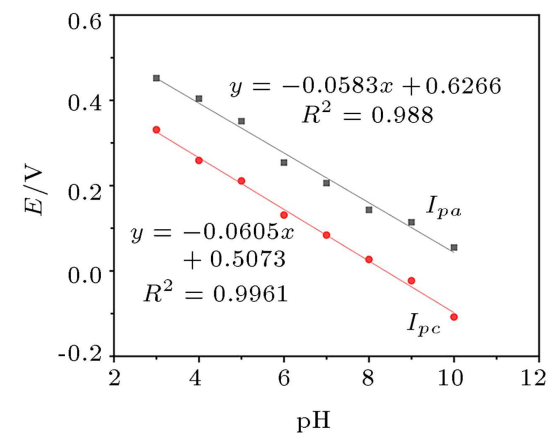

(a)

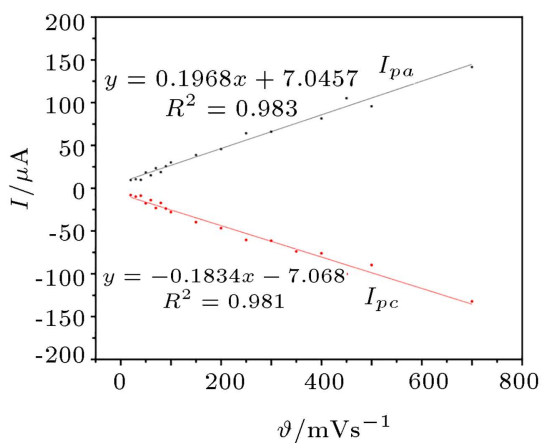

(b)

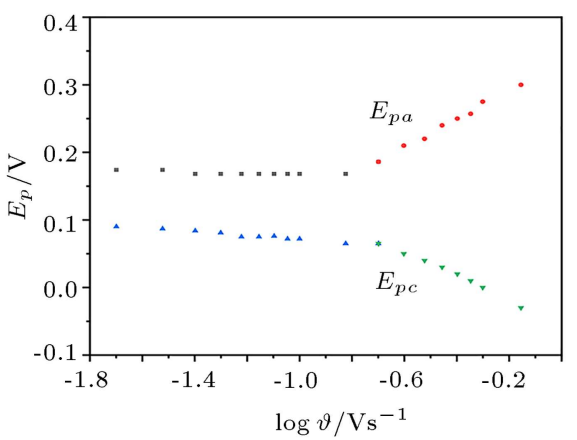

(c)

Figure 3. Variation of (a) $E_{p a}$ and $E_{p c}$ vs. pH, (b) $I_{p}$ vs. scan rate, and (c) $E_{p}$ vs. the logarithm of the scan rate in the range of $10-700 \mathrm{mV} \mathrm{s}^{-1}$. 


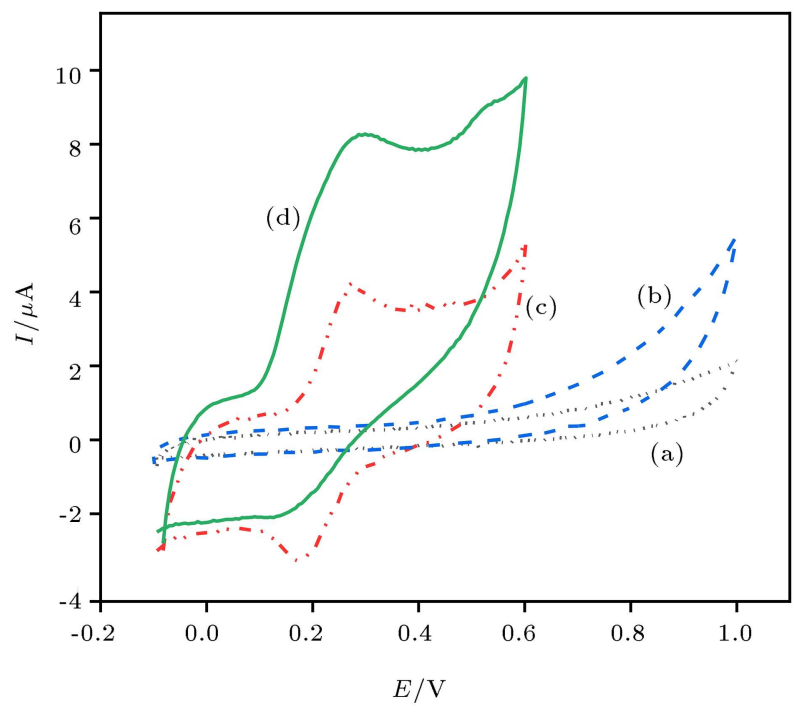

Figure 4. CVs of (a) bare GCE in a phosphate buffer solution ( $\mathrm{pH} 7.0$ ) at a scan rate of $20 \mathrm{mV} \mathrm{s}^{-1}$, (b) as (a) +0.2 mM GSH, (c) c-MWCNT/DPBDF-GCE in a phosphate buffer solution ( $\mathrm{pH} 7.0)$ at a scan rate of $20 \mathrm{mV}$ $\mathrm{s}^{-1}$, and (d) as (c) +0.2 $\mathrm{mM}$ GSH.

only some of the oxidized DPBDF could be reduced at the reverse scan. Figure 5(c) presents a Tafel plot for the sharply rising section of the current-potential curve.

\subsection{Study of interference}

The investigation of interferences with electrode responses helps minimize their effects on the preparation of electrodes. This study is partly concerned with how different foreign species affect the determination of $1.0 \times 10^{-4} \mathrm{M}$ GSH. The maximum concentration of those species was considered as the tolerance limit, leading to a relative error of $\pm 5 \%$ in GSH determination. The tolerated concentrations for the foreign

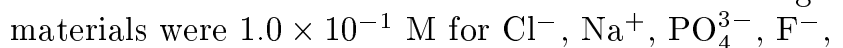
$\mathrm{CO}_{3}^{2-}, \mathrm{HCO}_{3}^{-}$and $\mathrm{K}^{+}, 1.0 \times 10^{-2} \mathrm{M}$ for glutamic acid and sucrose, $5.0 \times 10^{-3} \mathrm{M}$ for ascorbic acid, riboflavin, L-cysteine and glycine, and $2.5 \times 10^{-3} \mathrm{M}$ for folic acid.

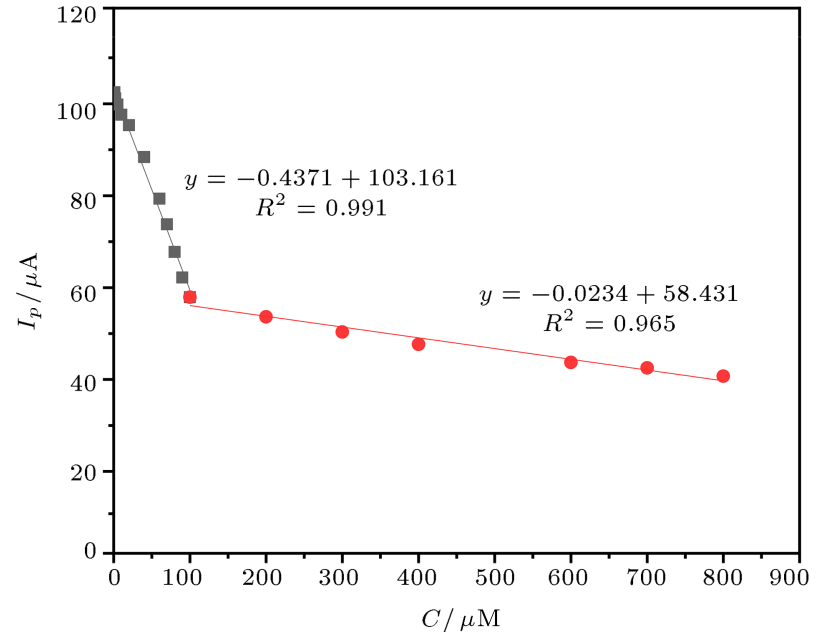

Figure 6. Calibration plot in a $0.1 \mathrm{M}$ buffer solution $(\mathrm{pH}$ 7.0) containing different concentrations of glutathione: (1) $1.0 \mu \mathrm{M}$, (2) $2.0 \mu \mathrm{M}$, (3) $5.0 \mu \mathrm{M}$, (4) $10.0 \mu \mathrm{M}$, (5) $20.0 \mu \mathrm{M}$, (6) $40.0 \mu \mathrm{M},(7) 60.0 \mu \mathrm{M},(8) 70.0 \mu \mathrm{M}$ (9) $80.0 \mu \mathrm{M},(10)$ $90.0 \mu \mathrm{M}$, (11) $100.0 \mu \mathrm{M}$, (12) $200.0 \mu \mathrm{M}$, (13) $300.0 \mu \mathrm{M}$, (14) $400.0 \mu \mathrm{M}$, (15) $600.0 \mu \mathrm{M}$, and (16) $800.0 \mu \mathrm{M}$.

\subsection{Calibration curve and detection limit}

The dynamic range and the sensitivity of the $\mathrm{C}$ MWCNT/DPBDF-GCE were evaluated in several concentrations of GHS. The findings are presented in Figure 6. The current response declined with a rise in the GSH concentration. These two parameters were linearly correlated within a range of $1.0 \mu \mathrm{M}$ to $800.0 \mu \mathrm{M}$. The peak current plot versus the GSH concentration had two linear sections with slopes of -0.437 and $-0.024 \mu \mathrm{A}_{\mu} \mathrm{M}^{-1}$ in the concentration range of $1.0-100.0 \mu \mathrm{M}$ and $100.0-800.0 \mu \mathrm{M}$, respectively. The low sensitivity of the second linear part may have been caused by certain kinetic constraints. A detection limit $(3 \sigma)$ of $0.73 \mu \mathrm{M}$ was found for $\mathrm{GSH}$.

\subsection{GSH determination in real samples}

Glutathione was determined successfully in several blood samples using the C-MWCNT/DPBDF-GCE.

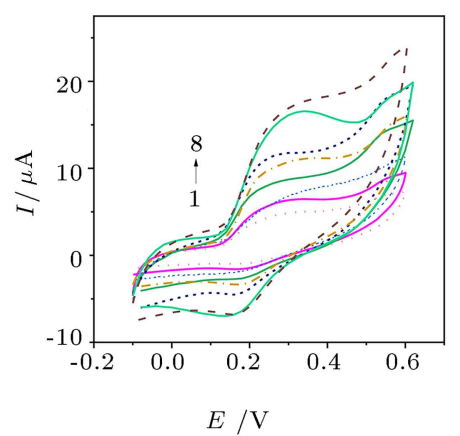

(a)

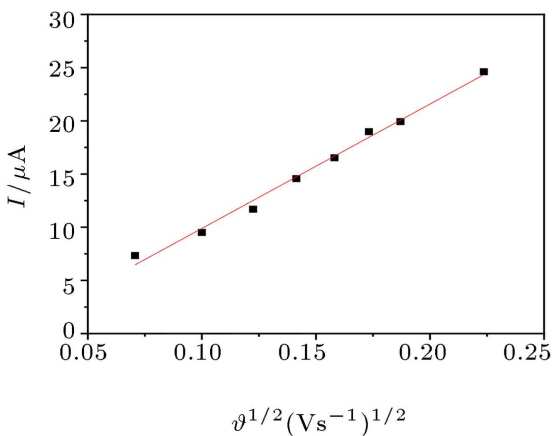

(b)

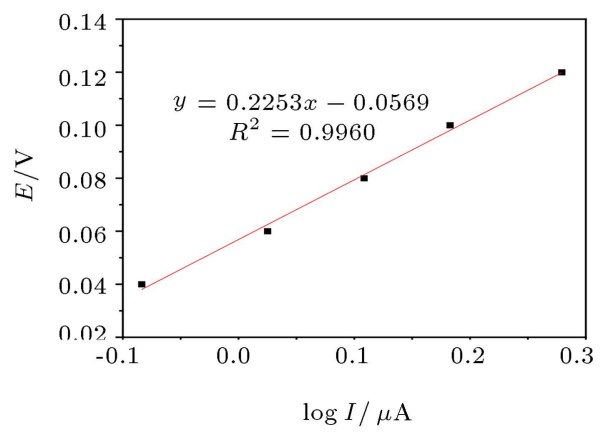

(c)

Figure 5. (a) CVs of c-MWCNT/DPBDF-GCE in a phosphate buffer solution (pH 7.0) containing $0.2 \mathrm{mM} \mathrm{GSH} \mathrm{at}$ different scan rates; numbers 1 to 8 correspond to $5,10,15,25,35,40,45$, and $50 \mathrm{mV} \mathrm{s}^{-1}$. (b) Shift of the anodic peak current vs. $\vartheta^{1 / 2}$. (c) Tafel plot derived from the rising part of the voltammogram recorded at a scan rate of $25 \mathrm{mVs}^{-1}$. 
Table 1. Recovery values for the voltammetric determination of a GSH standard solution added to three blood samples.

\begin{tabular}{ccccc}
\hline Sample GSH added $(\boldsymbol{\mu M})$ & GSH found $(\boldsymbol{\mu M})$ & Recovery $(\%)$ & RSD \\
\hline 1 & 0.0 & 54.146 & - & \\
2.0 & $56.126( \pm 0.361)$ & 99.00 & 0.643 \\
& & & & \\
2 & 0.0 & $55.458( \pm 0.729)$ & 102.20 & 1.314 \\
& 2.0 & & & \\
& & 27.561 & - & \\
3 & 0.0 & $29.487( \pm 0.314)$ & 96.32 & 1.065 \\
\hline
\end{tabular}

Briefly, $5 \mathrm{~mL}$ of each blood sample was put in a test tube, and its erythrocytes were separated by eliminating the plasma. For this purpose, the sample was centrifuged for 15 minutes at $3000 \mathrm{rpm}$ and $10^{\circ} \mathrm{C}$. The plasma that floated on the surface was discarded. What remained were erythrocytes that were then washed with a phosphate buffer solution $(\mathrm{pH} 7.0$ ) and $0.9 \% \mathrm{NaCl}$ for three times to eliminate any trace of the plasma left there. The erythrocyte pellets were hemolyzed in a $1.0 \mathrm{mmol} \mathrm{L}^{-1} \mathrm{Na}_{2} \mathrm{H}_{2}$ EDTA solution $(1: 1, \mathrm{v} / \mathrm{v})$. Then, 5-sulfosalicylic acid $(10 \%$ $(\mathrm{w} / \mathrm{v})$ was added to the prepared hemolyzed erythrocytes at a ratio of $2: 1(\mathrm{v} / \mathrm{v})$. The obtained solution was put under centrifuge at $3000 \mathrm{rpm}$ for 10 minutes. The supernatant material was collected for GSH measurements [36,37]. To check the applicability of this analytical method for real samples, it was used to measure GSH in three blood samples taken from people of different ages (32, 39, and 56 years). After separating the erythrocytes and diluting the solution according to the above-mentioned method, the samples were analyzed to determine GHS. To check against the matrix effect, the glutathione value was determined through a standard addition method. For this purpose, $20.0 \mu \mathrm{L}$ of $1000.0 \mu \mathrm{M}$ GSH spiked to $10 \mathrm{~mL}$ of each sample and, then, was analyzed through the described procedure. Table 1 presents the results of GSH determination in three different blood samples. Recovery of the empirical results was satisfactorily done for glutathione. The corresponding mean Relative Standard Deviation (RSD) confirmed the reproducibility of this method.

\section{Conclusion}

In this research, a new electrochemical biosensor was applied to determine GSH in real samples. Formazan was used as a modifier on the surface of a GCE, and that modifier proved to have a superior catalytic effect on GSH oxidation. Through cyclic voltammetry, it was found that GSH oxidation took place at a potential of about $+0.3 \mathrm{~V}$. The proposed procedure was shown to be fast, selective, and sensitive. It is also responsible for GSH determination and can be used to analyze real samples. Table 2 shows the results of this method and several other electrochemical methods practiced

Table 2. Comparison of the analytical data for the electrochemical determination of GSH.

\begin{tabular}{|c|c|c|c|c|c|c|}
\hline Electrode & Modifier & $\mathrm{pH}$ & $\begin{array}{c}\text { Detection } \\
\text { limit }(\mu \mathrm{M})\end{array}$ & $\begin{array}{c}\text { Linear } \\
\text { range }(\mu \mathrm{M})\end{array}$ & $\begin{array}{l}\text { Sensitivity } \\
\left(\mu \mathrm{A} \mu \mathrm{M}^{-1}\right)\end{array}$ & Ref. \\
\hline $\mathrm{GCE}$ & $\begin{array}{c}\text { Graphen oxide } \\
\text { nanosheets/hybride of } \\
\text { copper-cobalt } \\
\text { hexacyano ferrate }\end{array}$ & 3.0 & 0.25 & $0.33-55$ & 0.0682 & {$[38]$} \\
\hline $\begin{array}{c}\text { Nanocarbon } \\
\text { paset } \\
\text { electrode }\end{array}$ & Catechol & 7.5 & 3.2 & $1-100$ & 0.014 & {$[39]$} \\
\hline GCE & $\begin{array}{c}\text { Cobalt phthalocyanine/ } \\
\text { MWCNT }\end{array}$ & 7.4 & 100 & $500-7000$ & $9.7 \mu \mathrm{A} \mathrm{mM}^{-1}$ & {$[40]$} \\
\hline $\mathrm{GCE}$ & Copper (II) ione & - & 0.14 & $1-12.5$ & 0.1 & {$[41]$} \\
\hline
\end{tabular}


Table 2. Comparison of the analytical data for the electrochemical determination of GSH (continued).

\begin{tabular}{|c|c|c|c|c|c|c|}
\hline Electrode & Modifier & pH & $\begin{array}{c}\text { Detection } \\
\text { limit }(\mu \mathrm{M})\end{array}$ & $\begin{array}{c}\text { Linear } \\
\text { range }(\mu \mathrm{M})\end{array}$ & $\begin{array}{l}\text { Sensitivity } \\
\left(\mu \mathrm{A} \mu \mathrm{M}^{-1}\right)\end{array}$ & Ref. \\
\hline CPE & $\begin{array}{c}\text { Reduced graphene oxide/ } \\
\text { hydroquinone derivative } \\
\text { (DDDC) }\end{array}$ & 7.0 & 0.02 & $0.008-100$ & 0.043 & {$[42]$} \\
\hline $\mathrm{CPE}$ & $\begin{array}{l}\text { Co-based metal-organic } \\
\text { coordination polymer } \\
(\text { Co-MOCP })\end{array}$ & 5.5 & 80 & $2.5-950$ & - & {$[43]$} \\
\hline ITO & Annealed Nickel ion & 5.0 & 5 & $5-480$ & $66.7 \mu \mathrm{Acm}^{-2} \mu \mathrm{M}^{-1}$ & {$[44]$} \\
\hline $\mathrm{GCE}$ & $\begin{array}{c}\text { Ni-Al layered double hydroxides } \\
(\mathrm{Ni}-\mathrm{Al} \text { LDHs }) \\
\text { /MWCNTs }\end{array}$ & - & 0.7 & $1.2-1630$ & $120 \mu \mathrm{Acm}^{-2} \mu \mathrm{M}^{-1}$ & {$[45]$} \\
\hline SPE & CNTs & 7.0 & 3.0 & $10-100$ & - & {$[46]$} \\
\hline GCE & $\mathrm{Cu} /$ poly(thionine) (PTH) & 8.0 & $3.5 \times 10^{-3}$ & $0.01-1000$ & - & {$[47]$} \\
\hline $\mathrm{GCE}$ & c-MWCNTs/DPBDF & 7.0 & 0.73 & $\begin{array}{c}1.0-100.0 \\
100.0-800.0\end{array}$ & $\begin{array}{l}0.4371 \\
0.0234\end{array}$ & This work \\
\hline
\end{tabular}

for GSH determination. As suggested based on the comparative results, the method proposed in this study is advantageous in certain ways.

\section{Acknowledgements}

The authors wish to thank the Iran National Science Foundation (INSF), Yazd University Research Council and IUT Research Council and Excellence in Sensors for financial support of this research.

\section{Supplementary Material}

Supplementary material is available at:

http://scientiairanica.sharif.edu/jufile?ar_sfile=130305

\section{References}

1. Lagman, M., Ly, J., Saing, T., Singh, M.K., Tudela, E.V., Morris, D., Chi, P.T., Ochoa, C., Sathananthan, A., and Venketaraman, V. "Investigating the causes for decreased levels of glutathione in individuals with type II diabetes", PLoS One, 10(3), pp. 1-19 (2015).

2. Mazzetti, A.P., Fiorile, M.C., Primavera, A., and Lo Bello, M. "Glutathione transferases and neurodegenerative diseases", Neurochem Int, 82, pp. 10-18 (2015).

3. Pinnen, F., Sozio, P., Cacciatore, I., Cornacchia, C., Mollica, A., Iannitelli, A., Dâaurizio, E., Cataldi, A., Zara, S., Nasuti, C., and Di Stefano, A. "Ibuprofen and glutathione conjugate as a potential therapeutic agent for treating alzheimer's disease", Arch Pharm (Weinheim), 344(3), pp. 139-148 (2011).

4. Vidyasagar, M.S., Kodali, M., Prakash Saxena, P., Upadhya, D., Murali Krishna, C., Vadhiraja, B.M., Fernandes, D.J., and Bola Sadashiva, S.R. "Predictive and prognostic significance of glutathione levels and DNA damage in cervix cancer patients undergoing radiotherapy", Int J Radiat Oncol Biol Phys, 78(2), pp. 343-349 (2010).

5. Feng, J., Huang, P., Shi, S., Deng, K.Y., and Wu, F.Y. "Colorimetric detection of glutathione in cells based on peroxidase-like activity of gold nanoclusters: A promising powerful tool for identifying cancer cells", Anal Chim Acta, 967, pp. 64-69 (2017).

6. Allocati, N., Masulli, M., Di Ilio, C., and Federici, L. "Glutathione transferases: Substrates, inihibitors and pro-drugs in cancer and neurodegenerative diseases", Oncogenesis, 7(1), pp. 1-15 (2018).

7. Kowalska, K., Zalewska, M., and Milnerowicz, H. "The application of capillary electrophoresis in the determination of glutathione in healthy women's blood", $J$ Chromatogr Sci, 53(21), pp. 353-359 (2014).

8. Meister, A. "Glutathione metabolism and its selective modification", Journal of Biological Chemistry, 263(33), pp. 17205-17208 (1988).

9. Knapen, M.F.C.M., Zusterzeel, P.L.M., Peters, W.H.M., and Steegers, E.A.P. "Glutathione and glutathione-related enzymes in reproduction: A re- 
view", Eur J Obstet Gynecol Reprod Biol, 82(2), pp. 171-184 (1999).

10. Mills, B.J. and Lang, C.A. "Differential distribution of free and bound glutathione and cyst(e)ine in human blood", Biochem Pharmacol, 52(3), pp. 401-406 (1996).

11. Kand'ár, R., Žáková, P., Lotková, H., Kučera, O., and Červinková, Z. "Determination of reduced and oxidized glutathione in biological samples using liquid chromatography with fluorimetric detection", J Pharm Biomed Anal, 43(4), pp. 1382-1387 (2007).

12. Šegan, S., Opsenica, I., Zlatović, M., MilojkovićOpsenica, D., and Šolaja, B. "Quantitative structure retention/activity relationships of biologically relevant 4-amino-7-chloroquinoline based compounds", J Chromatogr B Anal Technol Biomed Life Sci, 1012-1013, pp. 144-152 (2016).

13. Ensafi, A.A., Khayamian, T., and Hasanpour, F. "Determination of glutathione in hemolysed erythrocyte by flow injection analysis with chemiluminescence detection", J Pharm Biomed Anal, 48(1), pp. 140-144 (2008).

14. Bergel, A., Souppe, J., and Comtat, M. "Enzymatic amplification for spectrophotometric and electrochemical assays of NAD+ and NADH", Anal Biochem, 179(2), pp. 382-388 (1989).

15. Wang, Z., Han, P., Mao, X., Yin, Y., and Cao, Y. "Sensitive detection of glutathione by using DNAtemplated copper nanoparticles as electrochemical reporters", Sensors Actuators, B Chem, 238, pp. 325330 (2017).

16. Majumder, M.K., Kaushik, B.K., and Manhas, S.K. "Novel spatially arranged mixed carbon nanotube bundle interconnects - Impact on delay and power", Sci Iran, 20(6), pp. 2341-2347 (2013).

17. Mazloum-Ardakani, M., Dehghani-Firouzabadi, A., Sheikh-Mohseni, M.A., Benvidi, A., Mirjalili, B.B.F., and Zare, R. "A self-assembled monolayer on gold nanoparticles modified electrode for simultaneous determination of isoproterenol and uric acid", Meas J Int Meas Confed, 62, pp. 88-96 (2015).

18. Gorgin Karaji, Z., Houshmand, B., Abbasi, S., and Faghihi, S. "Electrochemical anodic oxidation process of porous titanium granules for biomedical applications", Sci Iran, 22(6), pp. 2745-2751 (2015).

19. Mazloum-Ardakani, M., Farbod, F., and Hosseinzadeh, L. "An electrochemical sensor based on nickel oxides nanoparticle/ graphene composites for electrochemical detection of epinephrine", J Nanostruct, 6(4), pp. 293-300 (2016).

20. Mazloum-Ardakani, M., Ahmadi, S.H., Safaei Mahmoudabadi, Z., and Khoshroo, A. "Nano composite system based on fullerene-functionalized carbon nanotubes for simultaneous determination of levodopa and acetaminophen", Meas J Int Meas Confed, 91, pp. 162-167 (2016).
21. Faramarzi, V., Ahmadi, V., Ghane Golmohamadi, F., and Fotouhi, B. "A biosensor based on plasmonic wave excitation with diffractive grating structure", Sci Iran, 24(6), pp. 3441-3447 (2017).

22. AfzaliTabar, M., Alaei, M., Ranjineh khojasteh, R., Motiee, F., and Rashidi, A.M. "Preference of nano porous graphene to single-walled carbon nanotube (SWCNT) for preparing silica nano hybrid pickering emulsion for potential chemical enhanced oil recovery (C-EOR)", Sci Iran, 24(6), pp. 3491-3499 (2017).

23. Bagheri, Z., Ranjbar, B., Azizi, A., Latifi, H., Zibaii, M.I., and Tohidi Moghadam, T. "Plasmonic circular dichroism study of gold nanorod-quadruplex nanobioconjugates", Sci Iran, 25(3), pp. 1783-1788 (2018).

24. Shahmiri, M.R., Bahari, A., Karimi-Maleh, H., Hosseinzadeh, R., and Mirnia, N. "Ethynylferrocene$\mathrm{NiO} / \mathrm{MWCNT}$ nanocomposite modified carbon paste electrode as a novel voltammetric sensor for simultaneous determination of glutathione and acetaminophen", Sensors Actuators, B Chem, 177, pp. 70-77 (2013).

25. Yuan, B., Zeng, X., Xu, C., Liu, L., Ma, Y., Zhang, D., and Fan, Y. "Electrochemical modification of graphene oxide bearing different types of oxygen functional species for the electro-catalytic oxidation of reduced glutathione", Sensors Actuators, B Chem, 184, pp. $15-20$ (2013).

26. Munteanu, G., Dempsey, E., and McCormac, T. "Novel ultrasensitive and ultrafast voltammetric determination of biological aminochromes on the copper nanodoped mercury monolayer carbon fiber electrode", J Electroanal Chem, 650(1), pp. 105-115 (2010).

27. Wendland, T.R., Muntean, B.S., Kaur, J., Mukherjee, J., Chen, J., Tan, X., Attygalle, D., Collins, R.W., Kirchhoff, J.R., and Tillekeratne, L.M. V. "In situ self assembly of thiolated ortho-quinone capped electrocatalysts for bioanalytical applications", Electroanalysis, 23(10), pp. 2275-2279 (2011).

28. Calvo-Marzal, P., Chumbimuni-Torres, K.Y., Höehr, N.F., and Kubota, L.T. "Determination of glutathione in hemolysed erythrocyte with amperometric sensor based on TTF-TCNQ", Clin Chim Acta, 371(1-2), pp. 152-158 (2006).

29. Ndamanisha, J.C., Bai, J., Qi, B., and Guo, L. "Application of electrochemical properties of ordered mesoporous carbon to the determination of glutathione and cysteine", Anal Biochem, 386(1), pp. 79-84 (2009).

30. Tang, H., Chen, J., Nie, L., Yao, S., and Kuang, Y. "Electrochemical oxidation of glutathione at wellaligned carbon nanotube array electrode", Electrochim Acta, 51(15), pp. 3046-3051 (2006).

31. Abiman, P., Wildgoose, G.G., and Compton, R.G. "Electroanalytical exploitation of nitroso phenyl modified carbon-thiol interactions: Application to the low voltage determination of thiols", Electroanalysis, 19(4), pp. 437-444 (2007). 
32. Osorio, A.G., Silveira, I.C.L., Bueno, V.L., and Bergmann, C.P. " $\mathrm{H}_{2} \mathrm{SO}_{4} / \mathrm{HNO}_{3} / \mathrm{HCl}-$ functionalization and its effect on dispersion of carbon nanotubes in aqueous media", Appl Surf Sci, 255(5, Part 1), pp. 2485-2489 (2008).

33. Datsyuk, V., Kalyva, M., Papagelis, K., Parthenios, J., Tasis, D., Siokou, A., Kallitsis, I., and Galiotis, C. "Chemical oxidation of multiwalled carbon nanotubes", Carbon N Y, 46(6), pp. 833-840 (2008).

34. Nicholson, R.S. "Theory and application of cyclic voltammetry $\mathrm{f} \mathrm{m}$ measurement of electrode reaction kinetics", Anal Chem, 37(11), pp. 1351-1355 (1965).

35. Bard, A.J. and Faulkner, L.R., Electrochemical Methods: Fundamentals and Applications, Wiley (2000).

36. Anderson, M.E. "Determination of glutathione and glutathione disulphide in biological samples", Annu Rev Biochem, 113(1983), pp. 548-555 (1985).

37. Raoof, J.-B., Ojani, R., and Baghayeri, M. "Simultaneous electrochemical determination of glutathione and tryptophan on a nano-TiO2/ferrocene carboxylic acid modified carbon paste electrode", Sensors Actuators B Chem, 143(1), pp. 261-269 (2009).

38. Hassanvand, Z. and Jalali, F. "Electrocatalytic determination of glutathione using transition metal hexacyanoferrates (MHCFs) of copper and cobalt electrode posited on graphene oxide nanosheets", Anal Bioanal Chem Res, 5(1), pp. 115-129 (2018).

39. Lowinsohn, D., Lee, P.T., and Compton, R.G. "Towards detection of total antioxidant concentrations of glutathione, cysteine, homocysteine and ascorbic acid using a nanocarbon paste electrode", Int J Electrochem Sci, 9(7), pp. 3458-3472 (2014).

40. Olmos Moya, P.M., Martínez Alfaro, M., Kazemi, R., Alpuche-Avilés, M.A., Griveau, S., Bedioui, F., and Gutiérrez Granados, S. "Simultaneous electrochemical speciation of oxidized and reduced glutathione. Redox profiling of oxidative stress in biological fluids with a modified carbon electrode", Anal Chem, 89(20), pp. 10726-10733 (2017).

41. Areias, M.C.C., Shimizu, K., and Compton, R.G. "Voltammetric detection of glutathione: An adsorptive stripping voltammetry approach", Analyst, 141(10), pp. 2904-2910 (2016).

42. Benvidi, A., Dehghan, P., Dehghani-Firouzabadi, A., Emtiazi, H., Zare, H. R., and Mazloum-Ardakania, M. "Construction of a nanocomposite sensor by modification of carbon paste electrode with reduced graphene oxide and a hydroquinone derivative: Simultaneous determination of glutathione and penicillamine", Anal Methods, 7(1), pp. 5538-5544 (2015).
43. Yuan, B., Zhang, R., Jiao, X., Li, J., Shi, H., and Zhang, D. "Amperometric determination of reduced glutathione with a new Co-based metal-organic coordination polymer modified electrode", Electrochem Commun, 40, pp. 92-95 (2014).

44. Tian, H., Wang, T., Fu, Y., Yu, Y., Guo, C., and Hu, J. "Electrochemical determination of glutathione using an annealed nickel ion implanted-modified electrode", $J$ Electrochem Soc, 161(9), pp. 191-195 (2014).

45. Dong, Y., Sheng, Q., Zheng, J., and Tang, H., "A nonenzymatic reduced glutathione sensor based on Ni-Al LDHs/MWCNTs composites", Anal Methods, $6(21)$, pp. 8598-8603 (2014).

46. Lee, P.T., Goncalves, L.M., and Compton, R.G. "Electrochemical determination of free and total glutathione in human saliva samples", Sensors Actuators, B Chem, 221, pp. 962-968 (2015).

47. Liu, B., Ma, C., Li, Y., Kou, Y., Lu, J., Jiang, X., and Tan, L. "Voltammetric determination of reduced glutathione using poly(thionine) as a mediator in the presence of Fenton-type reaction", Talanta, 170, pp. 399-405 (2017).

\section{Biographies}

Mohammad Mazloum-Ardakani received BSc in Chemistry from University of Kashan, Kashan, Iran in 1986, MSc in Analytical Chemistry from Teacher Training University, Tehran, Iran in 1990, and his PhD in the same field from Isfahan University, Isfahan, Iran in 2000. He is a Professor of Analytical Chemistry at the Chemistry Department at Yazd University, Yazd, Iran. His main area of interest is electroanalytical chemistry and nanoelectrochemistry.

Zahra Tavakolian-Ardakani received BSc in Chemistry from Isfahan University, Isfahan, Iran in 1998 and MSc in Analytical Chemistry from the Department of chemistry of the Azad University, Yazd, Iran, in 2009. She is a PhD student of Analytical Chemistry at Yazd University, Yazd, Iran.

Seyed Hossein Banitaba received BSc in chemistry from Isfahan University of Technology, and his MS and PhD (2011) in Organic Chemistry from the University of Kashan, Iran. He is currently an Assistant Professor of Organic Chemistry at the Department of Chemistry at the Payame Noor University, Ardakan, Iran. His research interests include nanochemistry, nanocatalysts, organic synthesis, and NMR spectroscopy. 